\section{References}

1 Mihalopoulos C, Vos T, Pirkis J, Carter R. The economic analysis of prevention in mental health programs. Annu Rev Clin Psychol 2011; 7: 169-201.

2 Compton MT. Clinical Manual of Prevention in Mental Health. American Psychiatric Publishing, 2010.

3 Institute of Medicine. Reducing Risks for Mental Disorders: Frontiers for Preventive Intervention Research. National Academy Press, 1994.

4 Jorm AF. Mental health literacy: empowering the community to take action for better mental health. Am Psychol 2012; 67: 231-43.

5 Corrigan PW, Larson JE, Rüsch N. Self-stigma and the "why try" effect: impact on life goals and evidence-based practices. World Psychiatry 2009; 8: 75-81.

6 Schomerus G, Matschinger $\mathrm{H}$, Angermeyer MC. Preferences of the public regarding cutbacks in expenditure for patient care: are there indications of discrimination against those with mental disorders? Social Psychiatry Psychiatr Epidemiol 2006; 41: 369-77.

7 Clement S, Schauman O, Graham T, Maggioni F, Evans-Lacko S, Bezborodovs $N$, et al. What is the impact of mental-health related stigma on help-seeking? A systematic review of quantitative and qualitative studies. Psychol Med, 2014; in press.

8 Rüsch N, Heekeren K, Theodoridou A, Dvorsky D, Müller M, Paust T, et al. Attitudes towards help-seeking and stigma among young people at risk for psychosis. Psychiatry Res 2013; 210: 1313-5.

9 Corrigan PW, Watson AC. Factors that explain how policy makers distribute resources to mental health services. Psychiatr Serv 2003; 54: 501-7.

10 Rüsch N, Corrigan PW, Heekeren K, Theodoridou A, Dvorsky D, Metzler S, et al. Well-being among persons at risk of psychosis: the role of self-labelling, shame, and stigma-stress. Psychiatr Serv 2014; doi: 10.1176/ appi.ps.201300169.

\title{
Embracing autistic traits: Spock's Vulcan heritage in Star Trek
}

\section{Geoff Lawrence-Smith}

Star Trek has become a modern institution, a franchise spanning decades from the pilot episode in 1966 to J. J. Abrams' 2013 movie instalment, Star Trek: Into Darkness. Amidst its action and excitement, the success of the Star Trek series lies in its often perceptive social commentary.

Amid the tapestry of the Star Trek universe lies the Vulcan civilisation. Vulcans were once a barbarous and chaotic people who embraced ritualistic emotional control and the rigid discipline of logic to prevent their self-annihilation. In doing so, the Vulcans actively embraced characteristics the viewers might consider 'autistic' in order to aid their own survival. Indeed, the stigma Vulcans experience from others within the Star Trek universe parallels the stigma experienced by people with autism spectrum conditions in our own society.

Between the Vulcan and human cultures, the iconic character of Mr Spock strives to identify himself. Aboard the starship Enterprise, spock's continuing journey of self-discovery and understanding mirrors that of his culture's past and forms the backbone to his relationships with colleagues and friends. As Spock's character becomes better understood, he repeatedly demonstrates how his autistic traits serve him well when 'saving' the day.

Many perceive autistic traits in a negative way as rigid thinking, literal interpretation, tactlessness, non-conformity, and a disdain of aimless social interaction. In contrast, the character of Spock demonstrates logical, principled and methodological thinking, making astute appraisals of situations that he communicates to others without the need to obscure his ideas with social nuance and complexity. This is exemplified in Into Darkness, when Spock and Captain Kirk are reprimanded for insubordination.

'Admiral Pike: Are you giving me attitude, Spock?

Spock: I am expressing multiple attitudes simultaneously, sir. To which one are you referring?'

'Admiral Pike: That's a technicality.

Spock: I am Vulcan, sir. We embrace technicalities.'

Spock has always demonstrated an acute and immutable sense of social justice with an astounding eye for detail (especially concerning Starfleet regulations) which he often employs to temper Kirk's rash decision-making in critical situations.

'I can not allow you to do this [Captain]. It is my function aboard the ship to advise you in making the wisest decisions possible, something I firmly believe you are incapable of doing in this moment.' (Into Darkness)

'Nowhere am I so desperately needed as among a shipload of illogical humans.' (Star Trek, the original series)

Although he often misunderstands human motivations, Spock is a highly intelligent, autonomous and original thinker who notices patterns others rarely do. He is also a genuine and loyal friend who is immensely valued by those around him.

Kirk eulogising Spock: 'Of my friend, I can only say this: of all the souls I have encountered in my travels, his was the most . . . human.' (Star Trek: The Wrath of Khan)

Spock could be an all-too-rare positive role model for those with autism spectrum conditions, promoting, as he does, the value of 'autistic' attributes and reframing negative stereotypes of autism in a more positive light. 